\title{
Correction to: Transamidase site-targeted agents alter the conformation of the transglutaminase cancer stem cell survival protein to reduce GTP binding activity and cancer stem cell survival
}

\author{
C. Kerr · H. Szmacinski - M. L. Fisher - B. Nance - J. R. Lakowicz • A. Akbar • J. W. Keillor • T. Lok Wong • \\ R. Godoy-Ruiz $\cdot$ E. A. Toth $\cdot$ D. J. Weber $\cdot$ R. L. Eckert
}

Published online: 3 March 2021

(c) The Author(s), under exclusive licence to Springer Nature Limited 2021

Correction to: Oncogene

https://doi.org/10.1038/onc.2016.452
Following the publication of this article, the authors noted protein bands in the incorrect order in the blots in Figs. 3C, 4C. The corrected figures are given below.

These corrections have no impact on the experimental outcome or conclusions. 

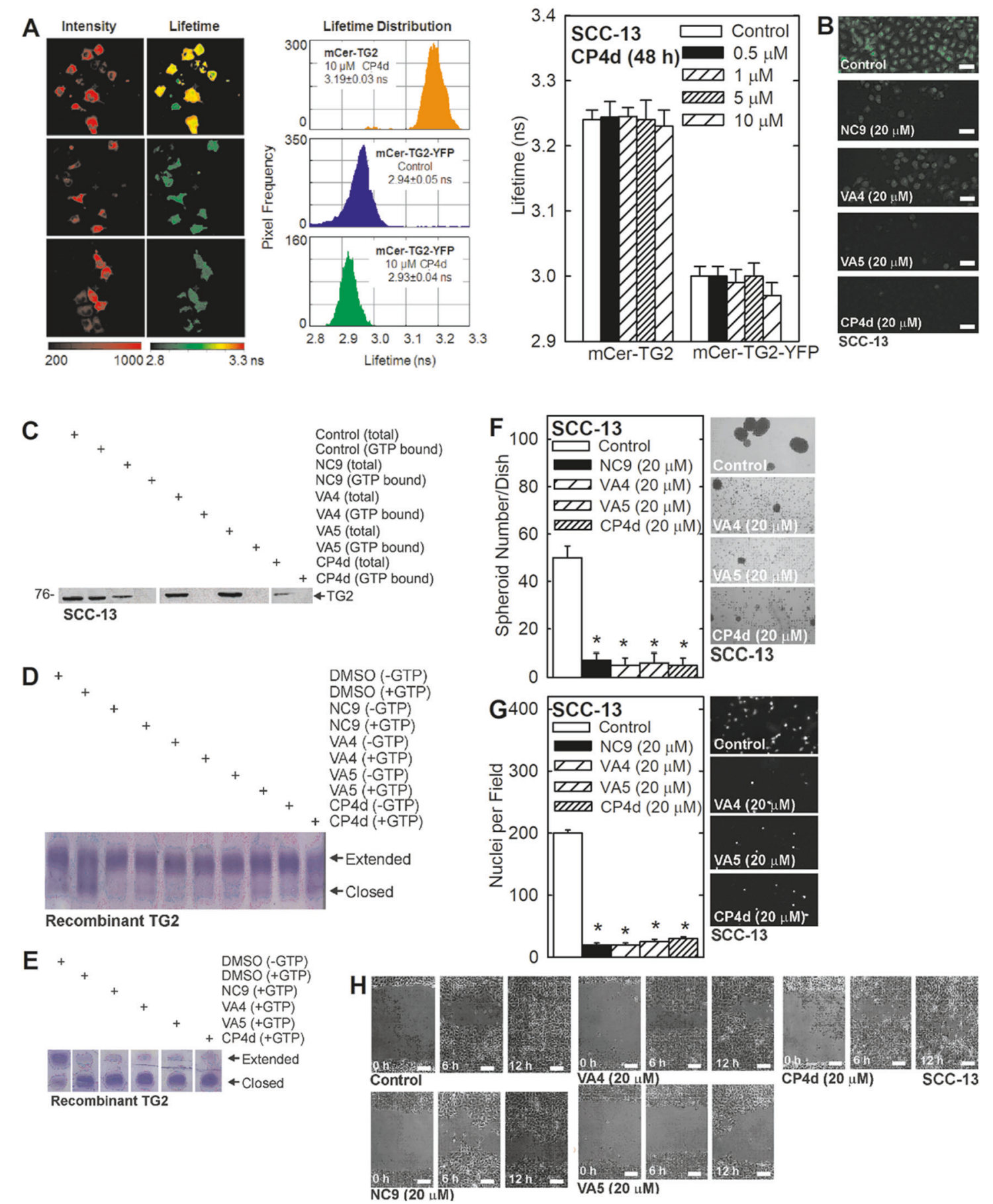

Authors Comment: The authors regret that the bands in Fig. $3 \mathrm{C}$ were mistakenly presented in the wrong order in the published manuscript. This corrects this mistake. This correction does not alter the outcome or conclusions of this figure or the manuscript.

Fig. 3 

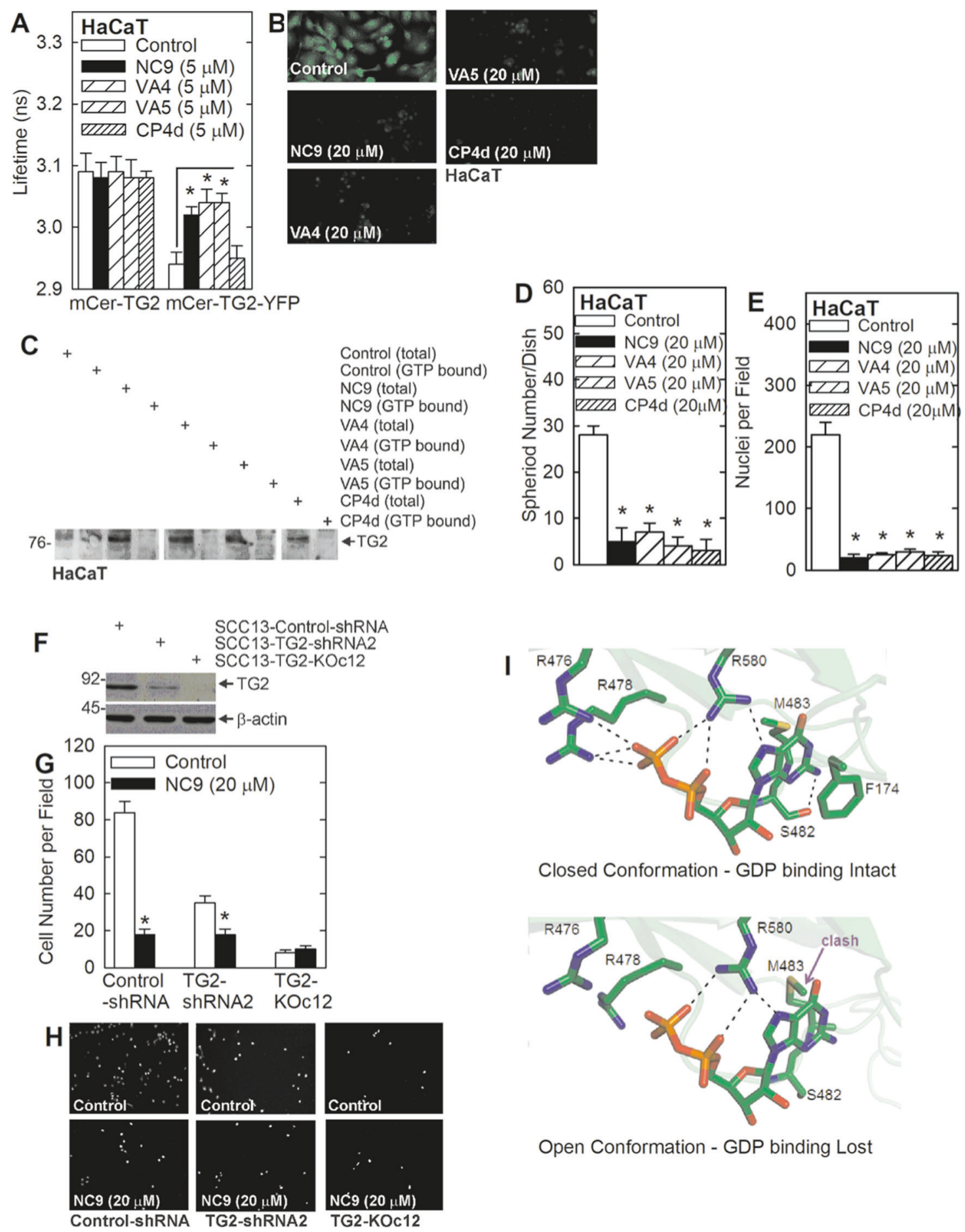

Closed Conformation - GDP binding Intact

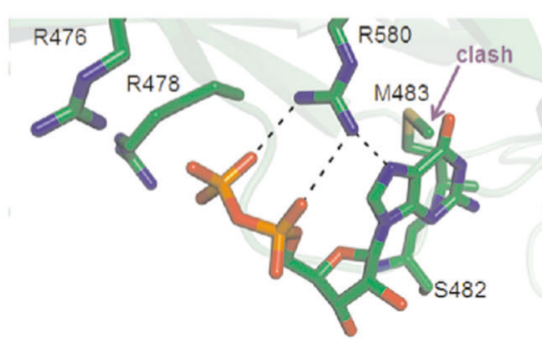

Open Conformation - GDP binding Lost

Authors Comment: The authors regret that the bands in Fig. 4C were mistakenly presented in the wrong order in the published manuscript. This corrects this mistake. This correction does not alter the outcome or conclusions of this figure or the manuscript.

Fig. 4 